\title{
A PARTICIPAÇÃO COMUNITÁRIA NA ANÁLISE DA AVALIAÇÃO DE IMPACTO AMBIENTAL COMO MECANISMO DEMOCRÁTICO DE GARANTIA DOS DIREITOS SOCIOAMBIENTAIS
}

José Cláudio Junqueira Ribeiro

Doutor em Saneamento, Meio Ambiente e Recursos Hídricos pela Universidade Federal de Minas Gerais (2005). Mestre em Genie Sanitaire et Urbanisme pela Ecole Nationale de La Sante Publique, Rennes, França (1977). Especialista em Engenharia Sanitária pela Escola de Engenharia da UFMG (1974). Graduado em Engenharia Civil pela Universidade Federal de Minas Gerais (1973). Professor titular de Gestão Ambiental da Faculdade de Engenharia e Arquitetura da Universidade Fumec e Professor permanente do Programa de Pós-graduação em Direito da Escola Superior Dom Helder Câmara: Mestrado em Direito Ambiental e Desenvolvimento Sustentável. Foi Pesquisador Pleno da Fundação Estadual do Meio Ambiente de Minas Gerais e seu Presidente por três mandatos, quando se aposentou. Consultor, atuando principalmente nas seguintes áreas: Sistema de Gestão Ambiental, Avaliação de Impacto, Licenciamento, Normalização, Resíduos Sólidos Urbanos RSU, de Serviço de Saúde RSS, e Eletroeletrônicos REEE e Indicadores Ambientais, de Produção mais Limpa e de Desempenho Ambiental. End. eletrônico: jcjunqueira@yahoo.com

ROMEU THOMÉ

Doutor em Direito Público com ênfase em Direito Ambiental pela Pontifícia Universidade Católica de Minas Gerais. Mestre em Direito Econômico com ênfase em Direito Ambiental pela Universidade Federal de Minas Gerais. Professor permanente do Programa de Pós-graduação em Direito da Escola Superior Dom Helder Câmara: Mestrado em Direito Ambiental e Desenvolvimento Sustentável. Advogado e consultor em Direito Ambiental.

\section{Resumo}

O presente trabalho tem como escopo analisar os mecanismos de participação popular na avaliação de impacto ambiental como decorrência da aplicação do princípio democrático em matéria ambiental. Verifica-se que, no Brasil, apesar de já prevista nas normas ambientais em vigor, a participação popular é limitada a momentos específicos do procedimento de licenciamento ambiental, enfraquecendo sua função de subsidiar a tomada de decisão pelo Poder Público e dificultando a adoção de medidas socioambientalmente justas. Uma das premissas de um Estado Democrático e Socioambiental de Direito 
é a de que os cidadãos têm o direito (e o dever) de participar ativamente da tomada de decisóes que possam vir a afetar o equilíbrio ambiental. Para tanto, torna-se necessário o aperfeiçoamento e a ampliação dos mecanismos de participação nos procedimentos de análise de avaliação de impactos ambientais.

\section{Palavras-chave}

Princípio democrático; Meio ambiente; Participação; Avaliação de impacto ambiental.

\section{Résumé}

Ce travail a pour objectif analyser les mécanismes de participation populaire dans l'évaluation de l'impact environnemental. Le thème est lié à l'application du principe démocratique en matière d'environnement. Il est constaté que, au Brésil, malgré déjà couverts par les normes environnementales, la participation populaire est limitée à des moments précis de la procédure d'autorisation. Cela affaiblit son rôle d'aider la décision prise par le gouvernement et entrave l'adoption de mesures socialement et écologiquement justes. Une des hypothèses d'un Etat de Droit Démocratique est que les citoyens ont le droit (et le devoir) de participer à la prise de décisions qui peuvent affecter l'équilibre environnemental. Pour cela, il est nécessaire l'amélioration et l'expansion des mécanismes de participation dans les procédures d'évaluation de l'impact environnemental.

\section{Mots-clés}

Principe démocratique; Environnement; Participation; L'évaluation de l'impact environnemental.

\section{Introdução}

As origens do processo de avaliação de impacto ambiental remontam ao final da década de 1960, período em que houve a elaboração do National Environmental Policy Act - NEPA nos Estados Unidos, vigente em primeiro de janeiro de 1970. Tão-logo implementados pelos norte-americanos, os mecanismos previstos no NEPA também foram adotados por países de economia central com estágios de desenvolvimentos similares, que igualmente sentiram a necessidade de elaboraçáo de avaliação de impactos ambientais para subsidiar a tomada de decisão do Poder Público, sobretudo nos projetos de empreendimentos de maior envergadura. Inicialmente, a disseminação desse processo de avaliação de impacto ambiental ocorreu em países de origem britânica, como Canadá (1973), Nova Zelândia (1973) e Austrália (1974), provavelmente em decorrência da similitude de seus sistemas políticos e jurídicos. 
Na Europa, a Diretiva 337/85 (que dispóe sobre a avaliação dos efeitos de determinados projetos públicos e privados no ambiente) é considerada o marco para a adoção formal do processo de avaliação de impacto ambiental, aplicada, a partir de então, compulsoriamente, em todos os países membros. Importa registrar, nesse ponto, a precursora iniciativa da França, que em 1976 legislou sobre esse tema, antecipando sua aplicação no território europeu.

As discussóes acerca da complexidade da temática ambiental, as cooperaçóes internacionais e a instauração de relaçóes com bancos internacionais, notadamente o Banco Mundial, constituíram-se em fatores relevantes para que a avaliação de impacto ambiental fosse introduzida também nos países em desenvolvimento.

No Brasil, conquanto alguns estados, a exemplo de São Paulo, Rio de Janeiro e Minas Gerais já ensaiassem procedimentos de avaliação de impacto ambiental desde meados dos anos 1970, sua implementação em âmbito nacional assumiu feição cogente apenas no início da década de 1980, por meio da Lei 6.938 de 31 de agosto de 1981, que alçou a avaliação de impactos ambientais à categoria de instrumento da política nacional de meio ambiente.

Art. $9^{\circ}$ - São instrumentos da Política Nacional do Meio Ambiente:

I - o estabelecimento de padróes de qualidade ambiental;

II - o zoneamento ambiental;

III - a avaliaçáo de impactos ambientais; (grifo nosso)

IV - o licenciamento e a revisão de atividades efetiva ou potencialmente poluidoras;

$\mathrm{V}$ - os incentivos à produção e instalação de equipamentos e a criação ou absorção de tecnologia, voltados para a melhoria da qualidade ambiental;

VI - a criação de espaços territoriais especialmente protegidos pelo Poder Público federal, estadual e municipal, tais como áreas de proteção ambiental, de relevante interesse ecológico e reservas extrativistas;

VII - o sistema nacional de informaçóes sobre o meio ambiente;

VIII - o Cadastro Técnico Federal de Atividades e Instrumentos de Defesa Ambiental;

IX - as penalidades disciplinares ou compensatórias ao não cumprimento das medidas necessárias à preservação ou correção da degradação ambiental.

X - a instituição do Relatório de Qualidade do Meio Ambiente, a ser divulgado anualmente pelo Instituto Brasileiro do Meio Ambiente e Recursos Naturais Renováveis - IBAMA;

XI - a garantia da prestação de informaçôes relativas ao Meio Ambiente, obrigando-se o Poder Público a produzi-las, quando inexistentes; 
XII - o Cadastro Técnico Federal de atividades potencialmente poluidoras e/ou utilizadoras dos recursos ambientais.

XIII - instrumentos econômicos, como concessão florestal, servidão ambiental, seguro ambiental e outros. (CONAMA, 1986).

Embora a avaliação de impactos ambientais tenha sido positivada com a Lei 6.938/81, a regulamentação dos procedimentos para sua efetiva aplicação somente ocorreu em 1986, por intermédio da Resolução 01/86 do Conselho Nacional de Meio Ambiente - CONAMA, diploma que estabeleceu as definiçôes, as responsabilidades, os critérios básicos e as diretrizes gerais para uso e implementação da Avaliação de Impacto Ambiental como um dos instrumentos da Política Nacional do Meio Ambiente.

Impóe-se destacar a ideia nuclear que anima os propósitos do National Environmental Policy Act - NEPA (1969), da Diretiva Europeia (1985) e da Resolução CONAMA (1986): a relevância atribuída à participação pública no processo de avaliação de impacto ambiental como garantia de pleno exercício de cidadania e democracia.

O presente trabalho tem como objetivo apresentar os conceitos centrais sobre participação em matéria ambiental, identificar a diversidade de público, e investigar os modelos e ferramentas disponíveis para a efetiva participação da sociedade nesse processo que oportuniza aos interessados o notável papel de atores na tomada de decisão pelo Poder Público. Ademais, cumpre destacar a importância da condução de um programa de participação e a efetiva incorporação de seus resultados no processo de análise da avaliação de impacto ambiental, à luz das normas que regulamentam seus procedimentos no ordenamento jurídico brasileiro e internacional.

\section{O Princípio Democrático (ou da Participação Comunitária) em Matéria Ambiental}

No Estado Democrático e Socioambiental de Direito $\left(^{1}\right)$, os cidadãos têm o direito (e o dever) de participar de decisóes que possam vir a afetar o equilíbrio ambiental. Há inúmeros mecanismos para proteção do meio ambiente que possibilitam a efetiva aplicação do princípio democrático (ou da participação comunitária).

O princípio dez da Declaração do Rio 92 (Eco 92) expressamente prevê que

$13 \mathrm{Na}$ literatura, encontram-se termos designativos de "Estado Ambiental de Direito", "Estado de Direito Ambiental”, "Estado Socioambiental”, "Estado Democrático Ambiental de Direito" e "Estado Democrático e Socioambiental de Direito", entre tantos, para denominar um Estado comprometido com a sustentabilidade ambiental. A rigor, Estado Democrático de Direito já assumiria inescapavelmente esse compromisso desde a largada. Mantivemos Estado Democrático e Socioambiental de Direito no texto como forma de enfatizar, dentre os projetos emancipatórios do Estado Democrático, o pacto intergeracional e o desenvolvimento sustentável num mundo de incertezas e riscos. 
[...] a melhor maneira de tratar questóes ambientais é assegurar a participaçáo, no nível apropriado, de todos os cidadáos interessados. No nível nacional, cada indivíduo deve ter acesso adequado a informaçóes relativas ao meio ambiente de que disponham as autoridades públicas, inclusive informações sobre materiais e atividades perigosas em suas comunidades, bem como a oportunidade de participar de processos de tomada de decisões. Os Estados devem facilitar e estimular a conscientização e a participação pública, colocando a informação à disposição de todos. Deve ser propiciado acesso efetivo a procedimentos judiciais e administrativos, inclusive no que diz respeito à compensaçáo e reparaçáo de danos. (grifo nosso).

A democracia, hoje, não se satisfaz com as instâncias deliberativas dos representantes eleitos e de corpos burocráticos fiéis aos comandos legais. Como ensina Sampaio (2003, p. 93), “o princípio do Estado Democrático de Direito não se consola apenas com a figura da representação política formal, exigindo simultaneamente a participação popular e a colaboração judicial responsável nos exercícios de concretização dos direitos fundamentais".

Ao defender a ideia de implementação de novos mecanismos calcados na ética de responsabilidade de longo alcance no agir humano, sobretudo no que se refere às questóes ambientais, Hans Jonas (2006, p. 64) questiona a capacidade do governo representativo contemporâneo de atender as novas exigências da sociedade de risco, acrescentando que “o 'futuro’ não está representado em nenhuma instância; ele não é uma força que possa pesar na balança. Aquilo que não existe não faz nenhum lobby, e os não-nascidos são impotentes". Nesse sentido, essencial agir, hoje, sob a luz dos princípios da precaução, da participação comunitária e do desenvolvimento sustentável, levando em consideração as necessidades das geraçóes futuras.

Para Hermitte e David (2004, p. 96), o sistema político "está diante da necessidade de reconstruir um mecanismo que permita avaliar os fatos científicos e técnicos para que a avaliação possa permitir uma decisão política conforme os padróes democráticos”. Para tanto, sustentam as autoras que "é preciso chegar ao 'conteúdo decisório dos conhecimentos', produzir os conhecimentos científicos com procedimentos que permitam o julgamento de terceiros".

Como se percebe, não se prescinde da participação direta do povo ou da comunidade tanto em sede de macro decisóes (plebiscito, referendo e iniciativa legislativa popular), quanto em processos decisórios de extensão setorial (decisóes administrativas, condominiais, empresariais, por exemplo), na medida em que essas deliberaçóes afetam, direta ou indiretamente, os indivíduos. (THOMÉ, 2015).

As questóes ambientais, por sua própria natureza, extensão e gravidade, enquadram-se como tema da macro democracia (consulta popular ambiental, como se deu 
na Itália e Suécia em relação à política nuclear) (MACHADO, 2004, p. 86) e da micro democracia (participação popular e social, sobretudo das ONGs, em audiências públicas e em açôes coletivas ambientais). (SAMPAIO, 2003, p. 80).

No Brasil, o princípio da participação comunitária encontra-se previsto no artigo 225, caput, da Constituição de 1988, na disposição que prescreve ao Poder Público e à coletividade o dever de defender e preservar o meio ambiente para as presentes e futuras gerações.

A sociedade passa, então, a ser detentora de alguns mecanismos de participação direta na proteção da qualidade de vida e dos recursos naturais, instrumentos hábeis a assegurar a manutenção do direito ao meio ambiente ecologicamente equilibrado de que é titular. (THOMÉ, 2015).

A participação comunitária em matéria ambiental pode se materializar sob diversas maneiras, como nos processos de criação do direito ambiental (por meio da iniciativa popular nos procedimentos legislativos, por exemplo) e na atuação do Poder Judiciário e do Ministério Público (por meio do ajuizamento de ação popular e ação civil pública ambiental). No presente trabalho, entretanto, será enfatizada a participação popular na formulação e na execução de políticas ambientais, por intermédio da atuação de cidadãos e representantes da sociedade civil em órgãos colegiados responsáveis pela formulação de diretrizes de políticas públicas e discussão de estudos de impacto ambiental em audiências públicas.

A participação da sociedade, nesses casos, tem a intenção de apresentar conhecimentos e percepçóes de cidadãos e grupos de interesse aos administradores públicos responsáveis por decisóes sobre temas ambientais. Esse mecanismo de consulta vem sendo denominado pela doutrina de participação cidadã ou de cidadãos, participação ou envolvimento público. Os grupos de interesse podem ser representantes dos setores da indústria, mineração, comércio, infraestrutura, planejamento, saúde, conservação e preservação ambiental, entre outros. Imperioso reconhecer que a participação de diversos grupos de interesse amplia o debate e se mostra essencial para o curso de um procedimento administrativo ambiental justo e equilibrado.

Náo se pode perder de perspectiva que a participação de representantes dos diversos setores da sociedade tem lugar a partir de um processo dialético cujo intuito é promover a compreensão do público sobre as características do empreendimento ou atividade que se deseja implantar e dos estudos ambientais elaborados com identificaçáo e quantificaçáo dos potenciais impactos significativos sobre os meios físico, biológico e socioeconômico. Além disso, impóe-se que todos os cidadãos disponham de condições de compreender os processos e mecanismos de análise das demandas econômicas e socioambientais, com as respectivas propostas de mitigação e compensação dos impactos negativos sobre o meio 
ambiente e sejam devidamente informados sobre o estado atual e o desenvolvimento dos estudos, seus resultados e prováveis intercorrências.

Vale destacar, por outro lado, que as opinióes e percepçóes da sociedade, sobretudo daqueles indivíduos ou grupos que serão diretamente impactados, são relevantes para a definição de solução viável que considere seus interesses prioritários e estabeleça estratégias de gestáo para o uso da área e de seus recursos naturais. Sob essa perspectiva, a participação ativa dos cidadãos ainda tem o condão de legitimar a decisão do Poder Público.

Nesse mesmo diapasão, a participaçáo dos indivíduos deve envolver tanto a alimentação como a retroalimentação de informaçóes. A alimentação é entendida como o processo pelo qual a informaçáo sobre o empreendimento ou atividade e seus potenciais impactos é disponibilizada aos cidadãos e grupos de interesse. Por retroalimentação compreende-se o processo no qual as percepçóes da sociedade em relação aos impactos socioambientais do empreendimento são recebidas pelo Poder Público, instrumentalizadas em informaçóes a serem efetivamente consideradas pelos tomadores de decisão.

As singularidades do programa de participação pública no processo de análise de avaliação de impacto ambiental impóem que os dados devam ser apresentados sinteticamente e adequados à razoável compreensão dos destinatários, com informaçóes claras e objetivas. Desse modo, técnicas de diálogos com toda a comunidade, hábeis a oportunizar ativamente a participação de indivíduos e organizaçóes interessadas, não podem ser olvidadas.

Mostra-se importante acentuar, nesse ponto, que o direito à participação pressupóe o direito de informação, pois há vínculo indissociável entre ambos. Neste passo, calha invocar a doutrina de Édis Milaré (2006, p. 163), ao apontar que "os cidadãos com acesso à informação têm melhores condições de atuar sobre a sociedade, de articular mais eficazmente desejos e ideias e de tomar parte ativa nas decisóes que lhes interessam diretamente."

Por conseguinte, desata a compreensão de que a efetiva implementação do Estado Democrático e Socioambiental de Direito exige o fortalecimento do princípio da obrigatoriedade de atuação estatal e do princípio democrático, com a participação da sociedade nas questóes ambientais, compreendendo a ação conjunta do Estado e da coletividade na preservação dos recursos naturais. (THOMÉ, 2015).

\section{A Participação Pública na Análise de Impacto Socioambiental como Ins- trumento de Implementação do Princípio Democrático}

O objetivo nuclear da participação pública é assegurar o exercício da cidadania e da democracia no processo de avaliação de impacto ambiental, momento em que os diversos 
atores envolvidos e potencialmente afetados, direta ou indiretamente, por projeto ou atividade, devem ter amplo acesso às informaçóes relacionadas ao seu impacto socioambiental, tanto positivos quanto negativos, para que possam externar sua opinião aos órgãos públicos competentes.

Canter (1977), ao analisar a importância da participação popular prevista no NEPA, destaca como objetivos mais relevantes: a) informação, educação e compreensão; b) identificação de problemas, necessidades e valores importantes; c) geração de ideias e resolução de problemas; d) reação e retroalimentação sobre as propostas; e) avaliação de alternativas e f) consenso e resolução de conflitos.

O primeiro objetivo identificado por Canter guarda relação com a educação dos cidadãos sobre o que é impacto ambiental e a importância da participação cidadã para a prática da democracia, além da divulgação de informaçôes sobre o andamento do estudo e resultados, bem como dados sobre possíveis impactos ambientais.

A identificação de problemas, necessidades e valores importantes, por sua vez, atine à relevância dos recursos ambientais para diversos segmentos do público em uma região. Além disso, este objetivo estaria relacionado à definiçã̃o de áreas com problemas e necessidades ambientais (CANTER, 1977).

O terceiro ponto anotado está direcionado à identificação de alternativas para solucionar as necessidades identificadas, como a implementação de medidas mitigadoras com o fito de eliminar ou diminuir os efeitos socioambientais adversos decorrentes do empreendimento.

O quarto objetivo estudado pelo pesquisador diz respeito à compreensão, pelo Poder Público, das percepçóes da comunidade sobre o projeto, seus impactos e possíveis soluçóes.

Já a avaliação de alternativas está estreitamente ligada à reação e retroalimentação no que tange ao fluxo das propostas, que pode conter informaçóes valiosas relacionadas a nuances ambientais até então desconsideradas (CANTER, 1977).

O último objetivo realçado pelo pesquisador atine à resolução de conflitos existentes em relação à ação proposta. Pode ser instrumentalizado pela mediação das diferenças e conflitos entre os vários grupos de interesse, pelo desenvolvimento de mecanismos de compensação dos impactos ambientais não mitigáveis e pelo esforço para alcançar uma opinião de consenso, evitando litígios judiciais onerosos e, não raras vezes, desnecessários (CANTER, 1977).

Lembra Rodrigo Zouain da Silva (2012) que,

pautado na realidade social bem como no ordenamento jurídico, o Direito Ambiental tem como objetivo, por meio de critérios racionais e 
pertinentes, estabelecer uma justiça social ambiental, respondendo às novas exigências do Direito Ambiental contemporâneo, promovendo um diálogo harmônico com ciências correlatas.

Esse esforço pelo consenso em relação aos impactos socioambientais negativos do empreendimento e suas respectivas medidas mitigadoras e compensatórias tem por fim legitimar uma decisão que reflita a justiça socioambiental para cada caso concreto.

Constata-se que atualmente os grandes empreendimentos, além de buscarem o cumprimento de todas as exigências estabelecidas pelos órgãos ambientais licenciadores, preocupam-se em adotar códigos de conduta com o intuito de evitar eventuais conflitos sociais. Assim, desenvolvem suas atividades visando não apenas a obtenção do consentimento estatal para exploração de atividade impactante (licenciamento ambiental), como também para a obtenção do que se convencionou denominar "licença social”. (DAIZY; DAS, 2013, p. 73).

\section{Identificação dos Vários Públicos para a Participação}

Investigar a participação da sociedade nos processos de avaliação de impacto ambiental pressupóe a identificação dos grupos envolvidos, com o consequente destaque dos atributos ínsitos a cada um deles. Para o NEPA, um primeiro grupo compóe-se por pessoas que são diretamente afetadas pelo projeto e vivem nas proximidades ou nas áreas possivelmente impactadas pelo projeto. Um segundo grupo é constituído por organizações para a proteção do meio ambiente que, geralmente, pretendem garantir que o desenvolvimento do projeto não promova um desequilíbrio nos ecossistemas. Os componentes desse grupo muitas vezes exigem a adoção de medidas que podem acarretar custos financeiros substanciais ou até mesmo inviabilizar a implantação do projeto.

Empreendedores, empresários, terceiros beneficiários da implantação do empreendimento e aspirantes aos futuros postos de trabalho formam o terceiro grupo. Observa-se também a participação de grupo formado por agentes governamentais interessados no fomento de investimentos para suas regióes de influência, na expectativa de geração de renda e dinamização da economia.

Existem ainda grupos com interesses diversificados, como os responsáveis por pesquisa acadêmica, ou aqueles compostos por indivíduos com interesses exclusivamente pessoais e, muitas vezes pontuais, nem sempre legítimos, como especuladores imobiliários e lobistas.

Nos Estados Unidos, no caso de projetos com intervenção nos recursos hídricos, a organização denominada Corpo de Engenheiros propóe a consideração dos seguintes públicos: a) os cidadãos individuais, que expressam suas preferências individualmente, 
e não participam de quaisquer grupos ou organizaçóes; b) grupos desportivos; c) grupos ambientalistas; d) organizaçóes de proprietários rurais; e) associaçóes de Comércio e Indústria; f) associaçóes de profissionais, tais como o Instituto Americano de Planejadores, Sociedade Americana de Engenheiros Civis e outros; g) instituiçóes de ensino, incluindo universidades, escolas secundárias e escolas profissionais; h) clubes de serviços e organizaçóes cívicas, incluindo clubes de serviços, como Rotary Club, Lions Club, entre outros; i) sindicatos; j) agências governamentais estaduais e locais, incluindo as comissóes, conselhos de planejamento de agências governamentais e individuais; k) políticos eleitos estaduais e locais; 1) as agências federais; $m$ ) outros grupos e organizaçóes urbanos, grupos de oportunidade econômica, clubes e associaçóes políticas, grupos minoritários e grupos religiosos; o) meios de comunicação, incluindo o pessoal de jornais, rádio e televisão.

A Diretiva 337, de 1985, da Comunidade Europeia estabeleceu a necessidade de participação pública no processo de tomada de decisão para os projetos de impactos significativos no meio ambiente, sujeitos à avaliação de impacto ambiental, e a previsão de disponibilizar ao público interessado as informaçóes concernentes aos demais projetos sujeitos a outras formas de avaliação, inclusive as informações relativas à isenção e aos motivos para a concessão da licença. A Diretiva 35, de 26 de maio de 2003, alterou as Diretivas 337/85 e 61/96, estendendo essa obrigação, além do acesso à justiça, também para planos e programas com potenciais impactos ao meio ambiente.

Essas diretivas consideram dois tipos de público: o primeiro, mais amplo, composto por indivíduos ou organizaçóes e associações legalmente constituídas. O segundo, denominado público interessado, composto por pessoas ou grupos diretamente afetados e organizaçóes não governamentais que tenham como finalidade a proteção do meio ambiente e cumpram os requisitos previstos em legislação nacional.

No Brasil, a Resolução CONAMA 01/86, que dispóe sobre a participação pública para discussão sobre o projeto e seus impactos ambientais considera, além dos órgáos da Administração, apenas um tipo de público.

Artigo 11 - Respeitado o sigilo industrial, assim solicitando e demonstrando pelo interessado o RIMA será acessível ao público. Suas cópias permanecerão à disposição dos interessados, nos centros de documentação ou bibliotecas do IBAMA e do estadual de controle ambiental correspondente, inclusive o período de análise técnica.

$\$ 1^{\circ}$ - Os órgãos públicos que manifestarem interesse, ou tiverem relação direta com o projeto, receberão cópia do RIMA, para conhecimento e manifestação,

$\$ 2^{\circ}$ - Ao determinar a execuçáo do estudo de impacto ambiental e apresentação do RIMA, o órgão estadual competente ou o IBAMA ou, quando couber o Município, determinará o prazo para recebimento dos 
comentários a serem feitos pelos órgáos públicos e demais interessados (grifo nosso) e, sempre que julgar necessário, promoverá a realização de audiência pública para informação sobre o projeto e seus impactos ambientais e discussão do RIMA. (CONAMA).

Observa-se, todavia, que a solicitação de realização de audiências públicas, único espaço previsto no ordenamento jurídico brasileiro para a participação dos indivíduos, pressupóe prévio enquadramento no rol de legitimados a fazê-lo. A Resolução CONAMA no 9, de 03 de dezembro de 1987, que estabeleceu os procedimentos para as audiências públicas sobre os relatórios de impacto ambiental (RIMA), identificou como grupos de interesse competentes para sua solicitação (art. $2^{\circ}$ ) entidades civis, Ministério Público e grupos de cinquenta ou mais cidadãos.

Art. $1^{\circ}$ - A Audiência Pública referida na RESOLUÇÃO CONAMA n. ${ }^{\circ}$ 001/86, tem por finalidade expor aos interessados o conteúdo do produto em análise e do seu referido RIMA, dirimindo dúvidas e recolhendo dos presentes as críticas e sugestóes a respeito.

Art. $2^{\circ}$ - Sempre que julgar necessário, ou quando for solicitado por entidade civil, pelo Ministério Público, ou por 50 (cinquenta) ou mais cidadãos, o Órgão de Meio Ambiente promoverá a realização de audiência pública.

$\$ 1^{\circ}$ - O Órgão de Meio Ambiente, a partir da data do recebimento do RIMA, fixará em edital e anunciará pela imprensa local a abertura do prazo que será no mínimo de 45 dias para solicitação de audiência pública.

$\$ 2^{\circ}$ - No caso de haver solicitação de audiência pública e na hipótese do Órgão Estadual não realizá-la, a licença concedida não terá validade.

$\$ 3^{\circ}$ - Após este prazo, a convocação será feita pelo Órgão Licenciador, através de correspondência registrada aos solicitantes e da divulgação em órgãos da imprensa local.

$\$ 4^{\circ}$ - A audiência pública deverá ocorrer em local acessível aos interessados.

$\$ 5^{\circ}$ - Em função da localização geográfica dos solicitantes, e da complexidade do tema, poderá haver mais de uma audiência pública sobre o mesmo projeto de respectivo Relatório de Impacto Ambiental - RIMA.

Art. $3^{\circ}$ - A audiência pública será dirigida pelo representante do Órgão licenciador que, após a exposição objetiva do projeto e do seu respectivo RIMA, abrirá as discussóes com os interessados presentes.

Art. $4^{\mathrm{o}}$ - Ao final de cada audiência pública será lavrara uma ata suscinta Parágrafo Único - Serão anexadas à ata, todos os documentos escritos e assinados que forem entregues ao presidente dos trabalhos durante a seção. 
Art. $5^{\circ}$ - A ata da(s) audiência(s) pública(s) e seus anexos, servirão de base, juntamente com o RIMA, para a análise e parecer final do licenciador quanto à aprovação ou não do projeto. (CONAMA 09/87)

Normas administrativas estaduais também especificam mecanismos de participação em matéria ambiental, a exemplo da Deliberação Normativa do Conselho Estadual de Política Ambiental - COPAM no 12, de 13 de dezembro de 1994, do Estado de Minas Gerais, que dispóe detalhadamente sobre a convocação e realização de audiências públicas, apresentando os procedimentos e os grupos de interesse legitimados a participar, nos termos seguintes:

Art. $1^{\circ}$ - Audiência Pública é a reunião destinada a expor à comunidade as informaçóes sobre obra ou atividade potencialmente causadora de significativo impacto ambiental e o respectivo Estudo de Impacto Ambiental - EIA, dirimindo dúvidas e recolhendo as críticas e sugestôes a respeito para subsidiar a decisão quanto ao seu licenciamento.

Parágrafo único - O COPAM poderá determinar Audiências Públicas para analisar planos, programas, atividades e empreendimentos que prescindam de EIA e RIMA e que possam estar causando ou vir a causar significativa degradação ambiental, indicando na convocação as informações indispensáveis para subsidiar a audiência.

Art. $2^{\circ}$ - As Audiências são eventos públicos, que permitem a presença de qualquer pessoa ou entidade interessada no assunto objeto de discussão.

Art. $3^{\circ}$ - A realização de Audiência Pública será promovida pelo Secretário Executivo do COPAM, sempre que julgar necessário, ou por determinação do Presidente do Conselho, do Plenário ou de Câmara Especializada, bem como por solicitação:

I - do Poder Público Estadual ou Municipal, do Estado de Minas Gerais;

II - do Ministério Público Federal ou do Estado de Minas Gerais;

III - de entidade civil sem fins lucrativos, constituída há mais de um ano e que tenha por finalidade social a defesa de interesse econômico, social, cultural ou ambiental, que possa ser afetado pela obra ou atividade objeto do respectivo EIA e RIMA.

IV - de grupo de 50 (cinqüenta) ou mais cidadãos que tenham legítimo interesse que possa ser afetado pela obra ou atividade, com indicação de representante no respectivo requerimento.

$\$ 1^{\circ}$ - A Secretaria Executiva do COPAM, a partir da data do recebimento do EIA e RIMA, fixará em edital e anunciará pela imprensa a abertura do prazo para solicitação de Audiência Pública, que será de no mínimo 45 (quarenta e cinco) dias.

$\$ 2^{\circ}$ - A convocação das Audiências Públicas será feita através de jornal de grande circulação no Estado de Minas Gerais, de periódico local ou 
regional e do Diário Oficial do Estado de Minas Gerais, com antecedência mínima de 15 (quinze) dias úteis.

$\$ 3^{\circ}$ - As Audiências Públicas serão realizadas sempre no município de localização ou da área de influência da obra, atividade, plano ou programa, tendo prioridade para escolha o município onde os impactos ambientais forem mais significativos.

$\$ 4^{\circ}$ - Se a área de influência da obra ou atividade abranger dois ou mais municípios, o Secretário Executivo do COPAM, poderá convocar mais de uma Audiência Pública, podendo realizá-la também na Capital do Estado.

$\$ 5^{\circ}$ - Serão determinadas pelo Secretário Executivo do COPAM o local, com condiçôes adequadas de infraestrutura e de acesso público, que resguarde a independência da reunião, bem como horário e demais providências para realização das Audiências Públicas.

$\$ 6^{\circ}$ - Constarão do edital de convocação da Audiência Pública pelo menos, as seguintes informaçōes:

I - Localizaçáo do empreendimento ou atividade;

II - Nome do Empreendedor;

III - Disponibilidade do RIMA (datas, horários e local);

IV - Data, horário e local de realização da Audiência Pública.

Art. $4^{\circ}$ - As Audiências Públicas de empreendimentos ou atividades sujeitas a EIA e RIMA serão realizadas durante o processo de análise e tramitação do Estudo de Impacto Ambiental na Fundação Estadual do Meio Ambiente, antes da apresentação às Câmaras do COPAM do Parecer Técnico por ela elaborado.

(...)

Art. $7^{\circ}$ - Serão convocados, para manifestação na Audiência Pública, o empreendedor e o coordenador da equipe multidisciplinar responsável pela elaboração do EIA e RIMA, assessorados pelos técnicos necessários ao completo esclarecimento da questáo.

Parágrafo único - No caso das Audiências Públicas previstas no Art. 1º, Parágrafo único, desta Deliberação, serão convidadas as entidades responsáveis pelo assunto em exame.

(...)

Art. 11 - O empreendedor deverá, no município em que e realizar a Audiência Pública, colocar o RIMA a disposição de todos os interessados, durante o período mínimo de quinze dias úteis anteriores à realização da Audiência.

Parágrafo Único - Deverá ser dada prévia e ampla publicidade a respeito do fato determinado no caput deste artigo. 
Art. 12 - Durante a audiência pública será mantido no recinto, para livre consulta dos presentes, pelo menos um exemplar do EIA e RIMA.

Art. 13 - As despesas que se fizerem necessárias, com a realização da Audiência Pública, serão custeadas pelo empreendedor.

Se, por um lado, critica-se o limitado rol de legitimados para solicitar a audiência pública ambiental, por outro é louvável a iniciativa do Poder Público de assegurar, em norma ambiental, a possibilidade de participação da sociedade nessa etapa do licenciamento ambiental. Importa lembrar que, uma vez requerida pelos legitimados, a audiência pública torna-se etapa obrigatória do procedimento de licenciamento ambiental. Desse modo, não realizada a oitiva pública, a licença ambiental será considerada inválida.

\section{Necessidade de Aperfeiçoamento dos Mecanismos de Informação do Pú- blico}

$\mathrm{Na}$ legislação internacional, a exemplo da NEPA e Diretivas Europeias, há previsão para que a informação à sociedade atinente aos impactos socioambientais de empreendimentos se dê por intermédio de avisos públicos (como através de comunicados em placas afixadas em locais de visibilidade na área do projeto), na mídia escrita falada e televisada (anúncios em jornais, por exemplo) e na rede internacional de computadores. Esses informes aos indivíduos devem acompanhar os principais relatórios e pareceres que instruem os processos de avaliação de impacto ambiental, oportunizando-se aos grupos de interesse a possibilidade de elaboração de questionamentos e solicitaçóes de complementação das análises já realizadas.

Vale destacar que, nos termos das diretivas europeias, os Estados membros devem definir prazos razoáveis para que os interessados efetivamente participem do procedimento de tomada de decisóes referentes à qualidade do meio ambiente.

Na União Europeia, a participação pública também é garantida a um Estado que possa ser afetado por impactos significativos de planos, programas e projetos de outro Estado membro, assegurando-se o acesso a todas as informaçóes sobre os possíveis efeitos transfronteiriços.

Os resultados das consultas nas diversas modalidades de participação pública devem sempre ser considerados na tomada de decisão sobre a aprovação dos planos, programas e projetos, como prevê a Diretiva 35/2003. Ademais, é obrigatório conferir publicidade às decisóes em matéria ambiental, que devem abordar as razóes em que se baseiam, as suas respectivas condiçóes, as medidas para evitar, mitigar ou compensar os impactos negativos da atividade, as opiniôes externadas pelo público interessado em relação ao impacto ambiental da atividade, além das demais informaçóes relativas à condução do procedimento de participação pública. 
Os Estados membros da União Europeia devem assegurar, em suas legislaçóes internas, que os interessados tenham acesso aos tribunais para impugnar atos, decisóes ou omissôes relativos à participação pública no processo de avaliação de impacto ambiental, sem prejuízo da possibilidade de interposição de recurso preliminar na esfera administrativa.

O ordenamento jurídico do Brasil, por sua vez, é tímido ao positivar instrumentos de informação e participação relacionados à avaliação de impactos ao meio ambiente. No âmbito de competência federal, a Resolução CONAMA 09/87 determina que o órgão ambiental licenciador anuncie o recebimento de avaliação de impacto ambiental de projetos e fixe, em edital, prazo para o requerimento de audiência pública. Havendo solicitação, o órgão licenciador deve proceder à efetiva convocação do interessado, com divulgação na imprensa local.

Observa-se, no Brasil, que alguns estados da federação, a exemplo de Minas Gerais, impóem obrigação complementares no que concerne à informação ao público. A Deliberação Normativa do Conselho Estadual de Política Ambiental - COPAM no 12, de 1994, do Estado de Minas Gerais, prevê o dever do empreendedor de divulgar a realização das audiências públicas não somente em órgãos de imprensa local, como também regional.

Ainda assim, constata-se a carência de mecanismos de interlocução entre a sociedade brasileira e o empreendedor sobre os impactos socioambientais das atividades potencialmente degradadoras. Vale lembrar que o dever de informação não pode ser meramente formal, mas, ao reverso, deve possibilitar diálogo hábil a, efetiva e materialmente, influir na decisão da autoridade ambiental.

\section{Análise Crítica da Participação Pública}

Como se percebe, a luzes claras, a participação ativa dos indivíduos no processo de investigação da avaliação de impactos ambientais tem o condão de legitimar a decisão do administrador público, na medida em que as pessoas diretamente afetadas pela atividade investigada encontram-se representadas em toda a extensão da avaliação ambiental, alçando esse processo de investigação de impactos ao meio ambiente à categoria de mecanismo imprescindível ao Estado Democrático e Socioambiental de Direito. Perspectivas de diversos grupos de interesse fornecem elementos úteis para subsidiar a tomada de decisóes, especialmente quando alguns valores ou fatores não podem ser facilmente quantificados.

Ademais, o processo de participação pública contribui para reforçar a credibilidade da atuação dos órgãos governamentais, especialmente no que se refere à tomada de decisão. Não remanescem dúvidas de que a análise da avaliação de impacto ambiental legitima-se com a participação dos interessados e diretamente afetados com a implantação do projeto. 
Por outro lado, os mecanismos de participação popular nas decisóes dos gestores em matéria ambiental não se encontram isentos de críticas. Argumentos contrários ao alargamento de legitimados a atuar no processo de investigação de impactos ambientais estruturam-se na inevitável pressão exercida pelos interessados sobre os administradores responsáveis pela tomada de decisão. Não se pode perder de perspectiva, ainda, que as sucessivas aberturas de prazos e os elevados custos relacionados à participaçáo popular tornam esses procedimentos burocráticos e dispendiosos ao Poder Público. Além disso, há o risco de demandas oportunistas, desvinculadas do objeto do projeto e de seus impactos ambientais que, inseridas no debate, dificultam e retardam a decisão por parte do órgão ambiental competente. Impóe-se destacar, neste ponto, que alguns interessados acabam por se desincumbir do seu poder-dever de tomar a devida ciência dos dados sobre o projeto que lhe são disponibilizados, interferindo negativamente no andamento das audiências públicas em razão da desnecessária prorrogação de atos que integram o procedimento.

Importa acentuar, ainda, singularidades ínsitas a países em desenvolvimento. No Brasil, o déficit social existente, não raras vezes, tem o condão de desvirtuar os procedimentos administrativos ambientais, situação usual, por exemplo, no momento da definição, pelo Poder Público, das medidas compensatórias como condicionantes no licenciamento ambiental do empreendimento. A participação popular, nesses casos, sinaliza por direcionar a compensação pelo impacto negativo do empreendimento para a adoção, pelo empreendedor, de melhorias nos setores de infraestrutura urbana, saneamento, educação e saúde. Essas medidas nem sempre se apresentam as mais indicadas para efetivamente compensar os impactos sobre o meio ambiente natural e, muitas vezes, incumbem ao próprio Estado e não ao responsável pelo empreendimento.

\section{Técnicas de Participação Pública}

Os programas de participação pública implementam-se a partir de diversas técnicas de alimentação e retroalimentação de informaçóes. A audiência pública constitui o meio mais tradicional de participação pública, adotada com frequência por diversos modelos internacionais analisados. A audiência pública consubstancia uma reunião formal na qual é franqueada a participaçáo de indivíduos e grupos de classe, que se comunicam oral ou por escrito, com registro em ata.

Além da audiência pública, existem outras técnicas que viabilizam a participação de interessados na avaliaçáo de impactos ambientais: apresentaçóes na fase de planejamento, elaboração participativa de termos de referência, sessóes informais para informação pública, oficinas relativas ao projeto, seminários, visitas de campo, material de divulgaçáo sobre o projeto e suas implicaçôes no meio ambiente, definição de medidas mitigadoras e compensatória, dentre outras. 
No que atine a exemplo bem sucedido de participação pública, releva mencionar o programa realizado conjuntamente pelos estados de Oklahoma e Kansas, na bacia do rio Arkansas. Este programa consistiu na realização de sete sessões de informação pública e treze oficinas específicas relacionadas ao projeto. Estas vinte reunióes foram realizadas em várias cidades e vilas da bacia. Em apertada síntese, podem ser enumerados os seguintes resultados: a) As vinte reunióes contaram com um total de 1.600 participantes. b) Os participantes não foram apenas os residentes das sedes das reunióes. Mais de quarenta por cento percorreram distâncias superiores a dez milhas, a partir das cidades de encontro. Assim, as pessoas foram atraídas de todas as partes da bacia. c) As perguntas e respostas em cada reunião foram caracterizadas pela participação ativa de muitos participantes. d) Os questionários de opiniáo sobre vários aspectos do estudo foram recebidos de mais de setenta por cento dos participantes. e) A análise dos resultados do questionário indicou que a maioria dos participantes considerou as reunióes muito produtivas. (CANTER, 1977).

Um dos aspectos que foi considerado a chave para o sucesso do referido programa norte-americano foi a parceria instaurada entre empreendedores e patrocinadores locais nos esforços para a promoção e realização dessas vinte reuniōes. Cada reunião consistiu em uma apresentação de slides, seguida de sessão informal com questionamentos e respostas, quando foram envidados todos os esforços para fornecer as informaçóes de interesse para o público. Além disso, foi entregue a cada participante material informativo sobre o projeto, seus impactos sobre o ambiente, e as respectivas medidas mitigadoras e compensatórias.

O programa de participação pública executado na bacia do rio Arkansas empregou diversas modalidades de técnicas de participação popular, viabilizando, em observância ao postulado do princípio democrático em matéria ambiental, a efetiva participação de representantes da sociedade civil. O Poder Público, nesse caso, promoveu a utilização de técnicas hábeis a possibilitar ativa participação pública antes de decidir em matéria ambiental, exemplo que deve ser seguido por outros programas de participação popular.

\section{Conclusões}

As normas brasileiras (Resoluçóes CONAMA 01/1986, 09/1987 e 237/97) que regulamentam o processo de avaliação de impacto ambiental seguiram os modelos estabelecidos nos Estados Unidos (NEPA, 1969) e nas Diretivas Europeias (CE 337/1985, 61/1996 e 35/2003). Nada obstante o Brasil ter importado os moldes mencionados, importa observar que, no ponto atinente à etapa prevista para se oportunizar participaçáo da sociedade civil, há diferenças relevantes. A legislação brasileira restringe a participação dos indivíduos na medida em que as audiências públicas estão previstas apenas na fase final do procedimento, quando a convicção do administrador público já se encontra em fase 
conclusiva de formação. Nesse momento, as percepçôes externas pouco podem influenciar na decisão do gestor.

Não basta oportunizar à sociedade civil a participação formal no processo de avaliação de impactos ambientais. A previsão desse instituto de participação democrática na legislação brasileira, nos moldes atuais, não assegura a atuação efetiva dos indivíduos. Convocar os interessados a participar do processo de avaliação de impactos ao meio ambiente apenas na sua etapa final não tem o condão de obstar decisões pré-estabelecidas no curso dos atos procedimentais.

A experiência brasileira não adota a prática de elaboração de um programa de participação pública que permeie todo o procedimento administrativo. O processo tem início à revelia dos públicos interessados, que sequer são identificados e convocados a participar dessa fase do processo de avaliação de impactos ambientais. Essa etapa preambular abrange a definição do escopo dos estudos ambientais a serem desenvolvidos, o acompanhamento do seu desenvolvimento, a implantação do projeto e o monitoramento do seu funcionamento, atos que não deveriam ser instaurados sem a necessária identificação e convocação da sociedade civil interessada na decisão ambiental final, sob pena de se fazer tábula rasa do postulado da participação democrática no Estado Socioambiental de Direito.

Outro viés da participação popular no processo de avaliação de impactos ambientais que carece de ajuste concerne aos critérios adotados no Brasil para a sua consecução. $\mathrm{Na}$ realidade, não existem critérios objetivos para a investigação de impactos ambientais. Esse processo é marcado pela ausência de especificação de aspectos positivos e negativos do empreendimento. Os referidos dados tornariam mais efetiva a participação pública durante todas as fases do projeto, pois a apresentação de tais elementos mostra-se fundamental para a construção de um real processo participativo de cidadania e democracia.

A materialização da participação popular nesse processo poderia ser alcançada, por exemplo, com a exigência de disponibilização, pelo empreendedor, de mais de uma alternativa viável para implantação do projeto, com as suas respectivas informaçóes e esclarecimentos sobre os impactos positivos e negativos, além da apresentação das medidas mitigadoras e compensatórias. $\mathrm{O}$ uso futuro da área afetada igualmente deve ser objeto de proposiçôes pelo empreendedor para oportunizar aos interessados participação ativa na decisão do Poder Público.

Conforme acentuado, a prática já difundida em território nacional de apresentar apenas a alternativa de projeto proposta pelo empreendedor desvirtua a participação popular, já restrita às audiências públicas, a um mero balcão de barganha de interesses, nem sempre legítimos, motivo pelo qual vêm sendo alvo de incisivas críticas, além de desqualificar essa tradicional técnica de participação popular em matéria ambiental. 
Como se percebe, para que a participação pública seja considerada um exercício efetivo de cidadania e democracia no Brasil mostra-se premente uma revisão dos mecanismos legais de participação atrelados à audiência pública ambiental. O modelo atual de participação pública na avaliação de impactos ambientais não atende à complexidade que permeia o instituto.

A dimensão material da participação democrática pressupóe poder de influência na decisão. A oitiva dos interessados deve ser considerada pela autoridade julgadora, que somente pode ser convencida pelas percepçóes externas quando são ofertados meios idôneos e tempestivos para a formação de sua convicção.

\section{Referências}

ALLES, Delphine. Le principe de precaution et la philosophie du droit - Evolution certaine, revolution en puissance. Grenoble: Université Pierre Mendès-France - Institut d'Etude Politique de Grenoble. 2011.

BECK, Ulrich. Sociedade do risco: rumo a uma outra modernidade. São Paulo: Ed. 34, 2010.

BOTHE, Michael. Le droit à la protection de l'environnement en droit constitutionnel allemand. Revue Juridique de l'Environnement. 1994. v. 4. p. 313-318.

CANOTILHO, José Joaquim Gomes. O direito ao ambiente como direito subjectivo. A tutela jurídica do meio ambiente: presente e futuro. Coimbra: Coimbra Editora, 2005.

CANTER, Larry W. Environmental Impact Assessment. New York, USA: McGraw-Hill Book Company, 1977.

DAYZY, Daizy; DAS, Niladri. Sustainable development for Indian mining sector (January 22, 2014), OIDA International Jorurnal of Sustainable Development, Vol. 06, n. 07, pp. 71-82, 2013. Disponível em: <http//ssrn.com/abstract=23833433>

EUROPA. Corte Europeia de Direitos Humanos. Affaire Matthews c. Royaume-Uni (Requête 24833/94), 18 de fevereiro de 1999. Disponível em: <http://zip.net/bsnz9c>. Acesso em 02 jun. 2014.

FRANÇA. Assembleia National. Rapport de la Commission de Lois Constitutionnelles relatif à la Charte de l'environnement. Paris: Assemblée Nationale, 2004. Disponível em: <http://bit.ly/U36lwi>. Acesso em 29 mai. 2014.

HERMITTE, Angèle; DAVID, Virginie. Avaliaçáo dos riscos e princípio da precaução. In: VARELLA, Marcelo Dias; PLATIAU, Ana Flávia Barros. Princípio da precaução. Belo Horizonte: Del Rey, 2004. p. 93-155. 
JONAS, Hans. O princípio responsabilidade: ensaio de uma ética para a civilização tecnológica; tradução do original alemão Marijane Lisboa, Luiz Barros Montez. Rio de Janeiro: Contraponto: Ed. PUC-Rio, 2006.

MACHADO, Paulo Affonso Leme. Direito Ambiental Brasileiro. 12a ed. Sáo Paulo: Malheiros, 2004.

MILARÉ, Edis. Direito do Ambiente. 4a . São Paulo: Editora Revista dos Tribunais, 2006.

PRIEUR, Michel. L'environnement entre dans la Constitution. Droit de l'Environnement, n. 106. Paris, 2003. p. 38-42.

SAMPAIO, José Adércio Leite. Princípios de Direito Ambiental. Belo Horizonte: Del Rey, 2003.

SILVA, Rodrigo Zouain da. Os desafios do direito ambiental no limiar do século XXI diante da ineficácia do sistema jurídico ambiental brasileiro. Belo Horizonte: Revista Veredas do Direito, v.9, n.18, p.57-87, julho/dezembro de 2012.

SANCHEZ, Luis Enrique. Avaliação de impacto ambiental: conceitos e métodos. São Paulo: Oficina de Textos, 2008.

THOMÉ, Romeu. Manual de Direito Ambiental. Salvador: Juspodivm, 2015. 